\title{
A study of aetiology and prevalence of malignancy in patients with post menopausal bleeding
}

\author{
Deepti D. Sharma*, Kavita A. Chandnani
}

Department of Obstetrics and Gynecology, GMERS Medical College Gotri, Vadodara, Gujarat, India

Received: 28 June 2017

Accepted: 25 July 2017

\section{*Correspondence:}

Dr. Deepti D. Sharma,

E-mail: deeptisharma_403@yahoo.co.in

Copyright: (C) the author(s), publisher and licensee Medip Academy. This is an open-access article distributed under the terms of the Creative Commons Attribution Non-Commercial License, which permits unrestricted non-commercial use, distribution, and reproduction in any medium, provided the original work is properly cited.

\begin{abstract}
Background: Post-menopausal bleeding (PMB) is a frequent and alarming sign and exclusion of genital tract malignancy should be the primary aim of investigation. Approximately 1 in 10 women experiences this problem. Increasing time interval between menopause and onset of post-menopausal bleeding is highly indicative of malignancy. Objectives of this study were to study the various etiologies and risk factors of post-menopausal bleeding and to find the prevalence of malignant pathology in women with post-menopausal bleeding.

Methods: Prospective observational study carried out in Obstetrics and Gynecology department of SBKSMIRC (Shrimati Bhikhiben Kanjibhai Shah Medical Institute and Research Centre), Dhiraj general hospital, comprising of 150 consecutive cases of postmenopausal bleeding occurring after one year of menopause, presenting in OPD or admitted in Gynecology or emergency ward with the same complaint. Patients were assessed clinically as well as thoroughly investigated to find out exact etiology. Pap smears, tranvaginal ultrasound, fractional curettage and biopsies were done. Statistical analysis of data was done after compiling and tabulation of data. Mean \pm SD for age and percentages for etiologies were calculated and compared with other studies.

Results: Benign aetiology was seen in $74 \%$ of the cases, malignant aetiology in $24 \%$ which is a significant proportion of menopausal women presenting with Post-menopausal bleeding. 58\% (87/150) patients were in the age group 50-59 and presented after five to ten years of menopause. Commonest benign aetiology was atrophic endometrium $25.4 \%$ and another $32.5 \%$ had functional endometrium as cause of PMB (proliferative 13.2\%, hyperplasia $13.2 \%$ and secretory $6.1 \%$ ). Among malignancies carcinoma cervix was the commonest, $52.7 \%$, (12.6\%) of study population followed by carcinoma endometrium, $25 \%$ (6\% of total population), thus making thorough and proper evaluation of all cases of PMB mandatory to pick up malignant lesions at early stage and initiate treatment accordingly.

Conclusions: Post-menopausal bleeding has become a common complaint in gynecology OPD and considering its possible association with malignancy, even slightest amount of bleeding demands proper work up.
\end{abstract}

Keywords: Cervical carcinoma, Endometrial carcinoma, Post-menopausal bleeding

\section{INTRODUCTION}

WHO has defined menopause as the permanent cessation of menstruation resulting from the loss of ovarian follicular activity. ${ }^{1}$ Postmenopausal bleeding (PMB) is defined as abnormal uterine bleeding occurring after one year of menopause. Common menopausal age in Indian women is around $42-50$ years. It is a common clinical problem, occuring in approximately $3 \%-5 \%$ of post menopausal women and represents one of the most common reasons for referral to gynaecological services, largely due to suspicion of an underlying genital tract malignancy. ${ }^{2,3}$ Aetiology of post menopausal bleeding includes benign causes like proliferative or atrophic 
endometrium, endometrial polyp or cervical polyp, endometrial hyperplasia (simple, complex with or without atypia) and malignant causes like endometrial carcinoma, cervical carcinoma, uterine sarcoma, oestrogen secreting ovarian tumours, vaginal and vulval carcinoma. $^{4}$

In developed countries incidence of post menopausal bleeding varies between 13 per 1000 post menopausal at age of 50 years and 2 per 1000 at age of 80 years (Gred Mark et al). ${ }^{5}$ There is $10 \%$ risk of having endometrial cancer in post menopausal bleeding women, whereas risk of cervical cancer is high in developing countries. The reported incidence of endometrial carcinoma has a very wide range from as low as $1.5 \%$ to as high as $54 \%$ in different population groups. 6,7

Being a symptom of varied aetiologies and strong association with malignancy, it warrants a thorough diagnostic evaluation, in order to identify the cause and to institute appropriate management at an early stage. ${ }^{8}$ This includes a complete history with assessment of various risk factors, medical history, and history of use of hormones and anticoagulants and clinical examination. Patient characteristics like multiparity, early marriage, multiple sexual partners, low socioeconomic status and poor hygiene are risk factors for cervical cancer whereas advanced age, obesity, early menarche, late menopause, hypertension, diabetes mellitus, nulliparity etc, can increase the probability of having endometrial cancer. ${ }^{3}$ Tissue diagnosis or biopsy is the gold standard for ascertaining the cause of PMB. For intracavitary lesions, office endometrial sampling or diagnostic dilatation and curettage, though invasive, are worldwide accepted procedures. $^{9}$ It can be supplemented by transvaginal ultrasound (TVUS), and hysteroscopy.

Hysteroscopy guided biopsies may be carried out in patients where office endometrial sampling fails, in cervical stenosis, persistent bleeding after negative biopsy or inadequate specimen. ${ }^{10-12}$ Ultrasound pelvis, being non-invasive, is an appropriate first-line procedure to identify which woman with post-menopausal bleeding is at higher risk of endometrial cancer. Endometrial thickness measurement by transvaginal ultrasound having a cut-off of $>4.0 \mathrm{~mm}$ may yield $98 \%$ sensitivity for the detection of endometrial cancer. Even endometrial hyperplasia, polyps, ovarian lesions can be easily picked up. ${ }^{13}$ Thus; it has become an integral part of PMB work up. Pap smear, a simple OPD procedure, though it has a low sensitivity (55-56\%) but high specificity (96-97\%), is considered mandatory primary investigation to pick up cervical precancerous lesions, whereas biopsy of frank cervical growth is diagnostic. ${ }^{2,14}$

Colposcopy can be instituted depending on the Pap smear report. Bleeding can be from non-gynaecological sites also, such as the urethra, bladder and lower gastrointestinal tract. Hormone replacement therapy as a cause of PMB is more common in developed countries.
Thus, the primary aim of investigating a woman with PMB is to exclude malignancy and any significant additional abnormality. The present study was carried out to ascertain various causes of PMB and to determine prevalence of genital tract malignancies as its cause and managing the cases accordingly in our population.

\section{METHODS}

A prospective observational study was conducted at obstetrics and gynecology department of SBKSMIRC (Shrimati Bhikhiben Kanjibhai Shah Medical Institute and research Centre), Dhiraj general hospital, Baroda, from January 2009 till January 2010 and 150 consecutive patients presenting with complain of PMB were selected form OPD, as well as those admitted in gynecology and emergency wards with same complaint were also included.

An informed consent was obtained and history was taken in detail mainly regarding age, parity, age of menarche, years since menopause, details of bleeding, any abnormal discharge, associated medical condition, use of drugs such as HRTs, tamoxifen and anti-coagulants, H/O any malignancy in family etc. The women having undergone hysterectomy and bilateral salpingo-oophorectomy, receiving radiotherapy or chemotherapy, suffered trauma to the genital tract, having coagulation disorder or on anticoagulant or hormone replacement therapy were excluded from the study.

Physical examination was conducted which included, after general examination, examination of abdomen for any mass, per speculum examination for local lesions of cervix (polyp, erosion, ectopy), ulcers on prolapse, tumours of vulva, vagina, cervix, atrophic vaginitis, bimanual examination for uterine size, mobility, position and adnexal masses, rectovaginal examination for nodularity in cul-de-sac and to decide stage in cases of frank carcinoma cervix. All the patients were subjected to Pap smear as OPD procedure only, except obvious cancer cervix. Relevant laboratory investigations were carried out, ultrasound scan was performed for all the patients especially for endometrial thickness, and appropriate biopsy specimen was obtained. The specimens from endometrial biopsy/curettage were sent for histopathological evaluation. The slides were reviewed and classified using current pathological WHO criteria. The endometrial specimens were divided into the following histological categories: atrophy; proliferation; secretion; endometrial polyp; simple or cystic hyperplasia; atypical hyperplasia; carcinoma and others.

\section{Statistical analysis}

All data was analyzed using the Microsoft Excel software. Statistical analysis of data was done after compiling and tabulation of data. Mean \pm SD were calculated for age, percentage was calculated for types of histopathological findings. 


\section{RESULTS}

Age distribution of the patients is depicted in Figure 1. Patients presenting with PMB comprised of $5.0 \%$ of all gynaecological outpatients in this study which is in accordance with the reported incidence of $4.1 \%$ and $5 \% .^{10,14}$

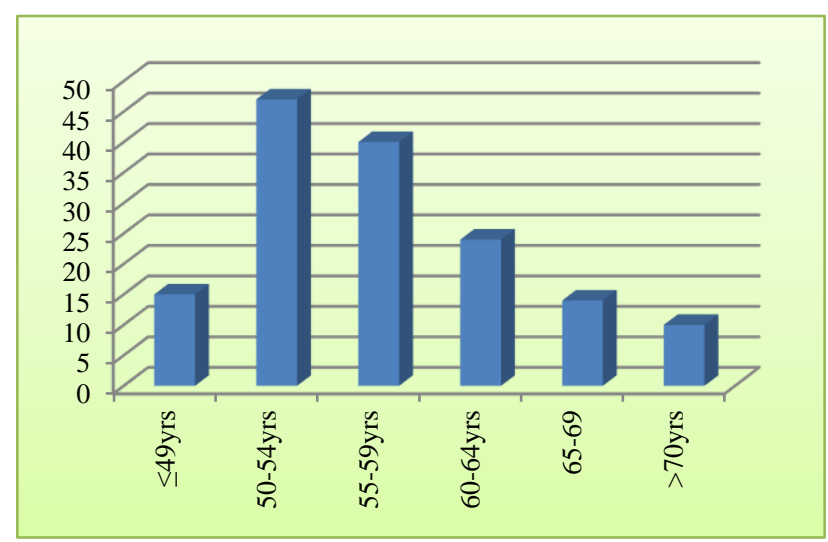

Figure 1: Age distribution of postmenopausal bleeding $(\mathbf{n}=150)$.

In present study population, benign histopathology of endometrium was more common comprising of $76 \%$ cases and incidence of malignancy was $24 \%$ (Table 1).

Table 1: Distribution according to aetiology.

\begin{tabular}{|lll|}
\hline Aetiological groups & Number (N) & $\%$ \\
\hline Benign cause & 114 & 76 \\
\hline Malignant cause & 36 & 24 \\
\hline Total & 150 & 100 \\
\hline
\end{tabular}

Table 2 shows the demographic distribution of the study population. The age of the patient at the time of consultation ranged from 44 to 80 yrs. The mean age was $57 \pm 2 \mathrm{yrs}$ and the most common time for the bleeding to occur was in the age group 50-60 years (87/150, 58\%), which was comparable to studies conducted by Sengupta et al and Peter at al. ${ }^{15,16}$

The mean age of menarche and menopause was $13 \pm 2$ yrs and $46 \pm 2$ yrs, respectively. $97 \%$ of our patients were multiparous with $63 \%$ having parity between 1-3 and $34 \%$ having more than three. Only 3 patients were nulliparous out which two had endometrial carcinoma while one was diagnosed to have fibroid. Postmenopausal bleeding was more common within 5-10 yrs after reaching menopause.

The interval between the cessation of menses and the onset of the postmenopausal bleeding ranged between one year and 20 years, the average being 7.7 years. Among the Medical conditions, only hypertension was seen in $16.6 \%(25 / 150)$ patients, while both hypertension and diabetes mellitus was seen in $6.6 \%$ (10/150), only diabetes was seen in only two patients.
Presence of both diabetes and hypertension increases the risk of endometrial hyperplasia and subsequently carcinoma, although being a developing country incidence of cervical carcinoma is more in India as compared to endometrial carcinoma.

Risk of endometrial cancer in women with PMB rises with age, peak incidence was observed in the age group of 55-70 yrs which was similar to those observed by Opmeer et al and Kothapally $\mathrm{K}$ et al. ${ }^{17,18}$ All the patients except those with frank ca cervix underwent dilatation and curettage.

Table 2: Distribution of benign and malignant aetiology according to age group, age at menopause and menopause to onset of PMB interval.

\begin{tabular}{|llll|}
\hline Age group (yrs) & Benign & Malignant & Total \\
\hline$\leq 49$ & 15 & 0 & 15 \\
\hline $50-54$ & 42 & 5 & $47(31.3 \%)$ \\
\hline $55-59$ & 29 & 11 & $40(26.7 \%)$ \\
\hline $60-64$ & 15 & 9 & $24(16 \%)$ \\
\hline $65-69$ & 8 & 6 & $14(9.3 \%)$ \\
\hline$>70$ & 5 & 5 & 10 \\
\hline Total & 114 & 36 & 150 \\
\hline Age at menopause (yrs) & & \\
\hline $41-45$ & 64 & 11 & $75(50 \%)$ \\
\hline $46-50$ & 44 & 19 & $63(42 \%)$ \\
\hline $51-55$ & 6 & 6 & 12 \\
\hline Total & 114 & 36 & 150 \\
\hline Menopause to & PMB interval (Yrs) & \\
\hline 1 & 10 & 0 & 10 \\
\hline $1-4$ & 50 & 4 & $54(7.4 \%)$ \\
\hline $5-9$ & 23 & 10 & $33(30.3 \%)$ \\
\hline $10-19$ & 26 & 17 & $43(39.5 \%)$ \\
\hline $20+$ & 5 & 5 & $10(50 \%)$ \\
\hline Total & 114 & 36 & 150 \\
\hline Parity & & & 3 \\
\hline Nulliparous & 1 & 2 & $95(63.3)$ \\
\hline $1-3$ & 83 & 12 & $52(34.6 \%)$ \\
\hline$>3$ & 30 & 22 & 150 \\
\hline Total & 114 & 36 & \\
\hline & & & \\
\hline
\end{tabular}

Table 3 shows the different histopathological findings on fractional curettage among benign aetiology, atrophic endometritis was most common followed by functional endometrium.

Combined endometrial thickness (CET) on TVUS ranged between $2 \mathrm{~mm}$ up to $18 \mathrm{~mm}$, with most of the patients having CET $<4 \mathrm{~mm}$ turned out to be atrophic endometritis $(25.4 \%$ ), those with CET between $5-8 \mathrm{~mm}$ mostly had proliferative (13.2\%) or disordered endometrium $(6.1 \%)$.

Patients with thickness $>10 \mathrm{~mm}$ showed hyperplasia (13.2\%, complex without atypia more common than simple) or endometroid carcinoma $(6 \%)$. 
Table 3: Distribution of benign causes of post menopausal bleeding $(n=114)$.

\begin{tabular}{|lll|}
\hline Cause & N & $\%$ \\
\hline Atrophic endometrium & 29 & 25.4 \\
\hline Proliferative endometrium & 15 & 13.2 \\
\hline Endometrial hyperplasia & 15 & \\
\hline Simple cystic & 06 & 13.2 \\
\hline Complex cystic & 09 & \\
\hline Atrophic vaginitis & 10 & 8.8 \\
\hline Endometrial polyp & 10 & 8.8 \\
\hline Cervical polyp & 6 & 5.3 \\
\hline Secretory/disordered proliferative & 7 & 6.1 \\
\hline Fibroid uterus & 5 & \\
\hline Decubitus ulcer & 7 & 6.1 \\
\hline Chronic cervicitis & 6 & 5.3 \\
\hline CIN I and III & 2 & 1.7 \\
\hline Pyometra & 1 & 0.8 \\
\hline Tb endometritis & 0 & \\
\hline Urethral caruncle & 1 & 0.8 \\
\hline Total & 114 & \\
\hline
\end{tabular}

In some cases, the curetting were scanty in spite of thick endometrium. This aberration may be due to endometrial polyps not amenable to blind curettage. Pap smear was done in all cases without frank growth on cervix and in majority it was inflammatory smear. One case had cervical intraepithelial neoplasia (CIN) III which was referred for colposcopy guided biopsy and follow up turned out to be carcinoma in situ. Total Abdominal hysterectomy with bilateral salpingo oophorectomy was done in that patient considering age and parity.
Table 4: Distribution of malignant causes of post menopausal bleeding $(n=36)$.

\begin{tabular}{|llll|}
\hline Cause & N & $\%$ & $\begin{array}{l}\% \text { in study } \\
\text { population } \\
(\mathbf{N}=150)\end{array}$ \\
\hline Carcinoma cervix & 19 & 52.7 & 12.6 \\
\hline Carcinoma endometrium & 9 & 25 & 6 \\
\hline Carcinoma ovary & 5 & 13.8 & 3.3 \\
\hline Ca vulva & 1 & 2.7 & 0.67 \\
\hline Ca vagina & 1 & 2.7 & 0.67 \\
\hline Ca bladder & 1 & 2.7 & 0.67 \\
\hline Total & 36 & & 23.91 \\
\hline
\end{tabular}

Table 4 shows malignant aetiologies responsible for PMB. Among the malignancies cervical cancer was the most common comprising $52.7 \%$ of malignant group while $12.5 \%$ of total population followed by endometrial cancer, $12.6 \%$ (65 of total population). High parity, early age at coitus, poor hygiene, low socioeconomic status, lack of awareness for available screening techniques, lack of access to health facilities, ignorance all contribute to high prevalence of cervical cancer in developing countries as seen in present study. Biopsy confirmed carcinoma cervix with proper staging was referred to appropriate centres for either Wertheim's hysterectomy, which were very few, or for radiotherapy which were comparatively more due to advanced disease at presentation. Among five patients having ovarian malignancy two had adult type granulose cell tumour which was diagnosed after HPE report of ovarian mass removed by laparotomy. The other three had epithelial ovarian malignancy.

Table 5: Comparison with other studies.

\begin{tabular}{|lllll|}
\hline Study & $\begin{array}{l}\text { Benign } \\
\text { aetiology }\end{array}$ & Malignant & $\begin{array}{l}\text { Ca cervix } \\
\text { \% of malignant lesions } \\
\text { (\% of total study population) })\end{array}$ & $\begin{array}{l}\text { Ca endometrium } \\
\text { \% of malignant lesions } \\
\text { (\% of total study population) }\end{array}$ \\
\hline Wondwossen et al & 39 & 61 & $82.8(51.6)$ & $31(6.5)$ \\
\hline Peter et al & 44 & 40 & $71.2(28)$ & $22.03(8.6)$ \\
\hline Kothakally et al & 82.7 & 16.6 & $60(10)$ & $40(6.6)$ \\
\hline Nasira et al & 84 & 16 & $20(3.2)$ & $32(8.3)$ \\
\hline Nirupama et al & 60 & 40 & $67.5(27)$ & $25(6)$ \\
\hline Present study & 76 & 24 & $52.7(12.6)$ & $(12)$ \\
\hline
\end{tabular}

Present results were comparable with studies conducted by Nirupama et al, Peter et al Kothapally et al and Wondwossen $\mathrm{E}$ et al, as in, all these studies showed higher percentage of patients with malignant aetiology of PMB to be having cervical carcinoma than endometrial carcinoma, however overall incidence of malignant aetiology was higher than benign aetiology in Wondwossen et al study in contrast to other studies. $^{4,16,18,19}$ This may be due to ethnic differences in the population. Nasira et al showed higher incidence of adenocarcinoma of endometrium as compared to cervical carcinoma, though overall malignant aetiology was $16 \% .{ }^{20}$ Majority of the cervical cancers were keratinising squamous cell carcinoma. Table 5 shows the comparison. Carcinoma vulva and vagina was very rare seen in one case each $(0.6 \%)$ beyond $70 \mathrm{yrs}$; they were referred to cancer institute. One case had carcinoma bladder which was also referred. 


\section{DISCUSSION}

Post-Menopausal bleeding must be considered as indicative of malignant disease until proven otherwise by Dr J. Glenn Bradley, still holds true. Currently men and women in India in the 60 plus age group number 60 million i.e. about $6 \%$ of the population. Projection for the year 2025 shows that aging population would increase to about $12 \%$ of the total and roughly half of this population will be women in the elderly age group. According to IMS (Indian menopause society) research there are about 65 million Indian women over the age of 45 . So, menopausal health demands even higher priority in Indian scenario. The rate of malignancy in PMB varies from country to country. It is difficult to know the true incidence of malignancy in postmenopausal bleeding because many patients may fail to seek medical care for this sign. ${ }^{19}$ In developed countries more than $60 \%$ cases are due to hormonal replacement therapy, benign lesions like atrophic vaginitis, polyp, endometrial hyperplasia and atrophic endometritis. ${ }^{21}$

The situation is different in developing countries and multiple studies conducted show a high prevalence of malignancy in patients of post menopausal bleeding. Most probably it reflects the non availability of screening programmes, poverty, lack of education and ignorance regarding women's health. The high prevalence of Human Immunodeficiency Virus (HIV) and Human Papilloma Virus (HPV) in the developing countries can as well be a significant contributor for the high rate of cervical malignancy. ${ }^{22}$ Overall, malignant aetiology of PMB in present study population was less $(24 \%)$ than benign aetiology (76\%); this may be due to lack of awareness of availability of facilities at this tertiary care centre among rural population and due to heterogeneous population.

A wide variety of benign causes were observed consistent with other studies. ${ }^{20}$ The reported incidence of malignancy in postmenopausal women has major differences in different population groups. It has been as low as $1 \%-1.5 \%$ in Jewish women probably due to low incidence of carcinoma cervix to as high as $54 \%$ in African women. ${ }^{6,7,23}$ The differences could be real based on different patterns of diseases according to geographic or ethnic differences or simply because of different selection criteria among various study populations. In this study, the causes of PMB in decreasing order of frequency were: atrophic endometritis $19.3 \%$, carcinoma cervix $12.6 \%$, proliferative endometrium $10 \%$, endometrial hyperplasia $10 \%$, carcinoma endometrium $6 \%$, atrophic vaginitis and endometrial Polyp 6\%, each. The ratio of malignancy in uterine corpus to cervix in present study was $1: 2$ as seen in study conducted by Capsi et al and Dawood et al. ${ }^{23,24}$

Patients with CET $>4 \mathrm{~mm}$ on transvaginal ultrasound showed either functional endometrium or hyperplastic endometrium, thus indicating that greater the CET on
TVS, higher the chances of malignancy. The risk of endometrial carcinoma increases with age with approximately $1 \%$ at age of 50 years to $25 \%$ at age $80 .{ }^{5}$ Management of the cases was done according to the current guidelines, atrophic endometrium or endometritis or benign endometrial polyps were managed conservatively and observed for any further similar complaint. Atrophic vaginitis was treated by local oestrogen creams, cervical polyps causing repeated episodes of bleeding were removed, some patients of chronic cervicitis demanded hysterectomy, simple and complex hyperplasia patients underwent hysterectomy, and carcinomas were managed according to stage of the disease.

In present study, the peak incidence of endometrial carcinoma was seen in the age group 55-64yrs as seen in study done by Burbos $\mathrm{N}$ et al whereas carcinoma cervix was more common beyond 60 yrs of age. ${ }^{25}$ Other genital tract malignancies were seen in relatively older age group (66-75). In present study only 5/150(3.3\%) cases of ovarian malignancy were seen which is similar to reported by others. ${ }^{26}$

Cervical cancer is a preventable cancer because it has a long preinvasive state and also the preinvasive stage can be detected by cervical cytology screening program, and because the treatment for preinvasive lesions is effective, screening for cervical cancer by examination of a cervical smear is widely recognized as leading to reduction in the mortality from cervical cancer. ${ }^{27}$

\section{CONCLUSION}

Women in their menopausal years are forming an increasingly large part of the local population. Post Menopausal bleeding always deserves investigation irrespective of how slight the bleeding is and even if had ceased, once the patient consults the clinician. It requires careful and timely assessment to eliminate the possibility of malignancy as soon as possible. Greater the interval between menopause and onset of PMB higher the chances of malignancy. Earlier diagnosis leads to a lower stage of disease, a less radical surgery, a therapy with fewer side effects and, subsequently, a better prognosis of affected patients.

\section{Funding: No funding sources \\ Conflict of interest: None declared \\ Ethical approval: Not required}

\section{REFERENCES}

1. WHO. Research on the menopause in the 1990s: report of a WHO scientific group. WHO Tech Report Series. 1996;866:1-107.

2. O'Gorman T. Post-menopausal bleeding. Recent Adv Obstet Gynecol. 2009;24:245-56. 
3. Hawwa ZM, Nahhas WA, Copenhaver EH. Postmenopausal bleeding. Lahey Clin Foundation Bull. 1970;19:61-70.

4. Nirupama V, Suneetha Y, Prabha Devi K. Post menopausal bleeding: an analytic study of 100 cases. Int J Sci Res. 2015;4(6):2588-90.

5. Gredmark T, Kvint S, Havel G, Mattsson LA. Histopathological findings in women with postmenopausal bleeding PV. Br J Obstet Gynecol. 1995;102:133-6.

6. Luiz DA, Moodley J, Richards A. Aetiology of postmenopausal bleeding in black women in Durban. S Afr Med J. 1986;69:674-5.

7. Gambrell RD, Castaneda JA, Ricci CA. Management of post menopausal bleeding to prevent endometrial cancer. Maturitas. 1978;1:99-105.

8. Gerber B, Krause A, Muller H, Reimer T, Kulz T, Makovitzky $\mathrm{J}$ et al. Effects of adjuvant tamoxifen on the endometrium in postmenopausal women with breast cancer: a prospective long term study using transvaginal ultrasound. J Clin Oncol. 2000;18:346470 .

9. Angioni S, Loddo A, Milano F, Piras B, Minerba L, Melis GB. Detection of benign intracavitary lesions in postmenopausal women with abnormal uterine bleeding: a prospective comparative study on outpatient hysteroscopy and blind biopsy. J Minim Invasive Gynecol. 2008;15(1):87-91.

10. Guruwadayarhalli B, Jones SE, Srinivasan V. Hysteroscopy in the diagnosis of postmenopausal bleeding. Menopause Int. 2007;13:132-4.

11. Buchanan EM, Weinstein LC, Hillson C. Endometrial cancer. Am Fam Physician. 2009;80:1075-80.

12. Lin HH, Wu MY, Shyu MK, Chen D, Tsai JL, Hsieh CY. Clinical study of 381 postmenopausal bleeding patients. J Formos Med Assoc. 1993;92:241-4.

13. Ferrazzi E, Torri V, Trio D, Zannoni E, Filiberto S, Dordoni D. Sonographic endometrial thickness: a useful test to predict atrophy in patients with postmenopausal bleeding. An Italian multicenter study. Ultrasound Obstet Gynecol. 1996;7:315-21.

14. Moodley M, Roberts C. Clinical pathway for the evaluation of postmenopausal bleeding with an emphasis on endometrial cancer detection. J Obstet Gynecol. 2004;24:736-41.

15. Sengupta A. A study of 50 cases of post menopausal bleeding. J Obstet Gynecol India. 1989:577-581.

16. Chew PCT, Ratnam SS. Post menopausal bleeding, a clinical review of 150 cases. Singapore Med J. 1972;13(1):29-32.
17. Opmeer B, vanDoorn $\mathrm{H}$, Heintz A, Burger C, Bossuyt $\mathrm{P}$, Mol B. Improving the existing diagnostic strategy by accounting for characteristics of the women in the diagnostic workup for postmenopausal bleeding. JOG. 2007;114:51-58.

18. Kothapally K, Bhashyakarla U. Postmenopausal bleeding: clinicopathologic study in a teaching hospital of Andhra Pradesh. Int J Reprod Contracept Obstet Gynecol. 2013;2(3):344-8.

19. Ergete W, Tesfaye A. Histopathological findings of Post-Menopausal bleeding in Ethiopian women. Ethiop J Health Dev. 2001;15:39-44.

20. Dawood NS, Peter K, Ibrar F, Dawood A. Postmenopausal bleeding: causes and risk of genital tract malignancy. J Ayub Med Coll Abbottabad. 2010;22(2):117-20.

21. Hacker NF, Moore JG, Essential of obstetrics and Gynecology. Philadelphia Wb Saunders;1986:465.

22. Eluf-Netol J, Booth M, Mufnoz N, Bosch FX, Meijer CJLM, Walboomers JMM. Human papillomavirus and cervical cancer in Brazil. Br. J. Cancer. 1994;69:114-9.

23. Caspi E, Perpinial S, Reif A. Incidence of malignancy in Jewish women with postmenopausal bleeding. Israel J Med Sci. 1977;13:299-304.

24. Dawood NS, Peter K, Sultana N, Mubarik A. Clinico-pathlogical pattern of gynaecological malignancies amongst families of ex service men. J Med Sci. 2009;17(2):95-8.

25. Burbos N, Musonda P, Giarenis I, Shiner AM, Giamougiannis $\mathrm{P}$, Morris $\mathrm{E}$ et al. Age-related differential diagnosis of vaginal bleeding in postmenopausal women: a series of 3047symptomatic postmenopausal women. Menopause Int. 2010;16(1):5-8.

26. Hamilton W, Peters TJ, Bankhead C, Sharp D. Risk of ovarian cancer in women with symptoms in primary care: population based case-control study. BMJ. 2009;339:b2998.

27. Miller AB, editor. Cancer screening. Cambridge University Press. Geneva;1991.

Cite this article as: Sharma DD, Chandnani KA. A study of aetiology and prevalence of malignancy in patients with post menopausal bleeding. Int J Reprod Contracept Obstet Gynecol 2017;6:3973-8. 